\title{
Filling OpenStreetMap data gaps in rural Nepal: a digital youth internship and leadership Programme
}

\author{
Kshitiz Khanal $^{1 *} \mathbb{B}$, Nama Raj Budhathoki ${ }^{1}$ and Nancy Erbstein ${ }^{2}$
}

\begin{abstract}
Crowdsourced, open geospatial data such as the data compiled through OpenStreetMap have proven useful in addressing humanitarian, disaster and development needs. However, the existing ways in which volunteers engage in OpenStreetMap have inherent limitations that lead to critical data gaps in economically underdeveloped countries and regions. Various initiatives that target specific geospatial data gaps and engage volunteers for longer periods have emerged to overcome these limitations, yet there has been limited in-depth study of such targeted mapping initiatives. This article reports the findings from Digital Internship and Leadership (DIAL), a programme designed to fill data gaps in rural Nepal by engaging young people in mapping rural Nepal by integrating targeted mapping, a virtual internship strategy and youth leadership development. The findings suggest the potential benefits of targeted mapping initiatives embedded in youth leadership internship programmes to address those critical data gaps.
\end{abstract}

Keywords: Contributor engagement, Crowdsourcing, OpenStreetMap, Targeted mapping initiatives, Youth mapping

\section{Introduction}

Crowdsourced, open geospatial data have been proven to be crucial for addressing humanitarian issues, disaster management and sustainable development. OpenStreetMap (OSM), a worldwide online digital map to which anyone can contribute by adding new or editing existing georeferenced information, is acclaimed as the largest freely and openly accessible geospatial database in the world [1]. Despite concerns about the quality and completeness of its underlying data, OSM has become increasingly vital, as it is the only source of geospatial information available in some parts of the world $[2,3]$. For example, data in OSM were used extensively to respond to the 2010 earthquake in Haiti and the 2015 earthquake in Nepal. OSM has also been used to document refugee and slum settlements, female genital mutilation and access to health services. OSM data, and other open data in general, can help in addressing the

\footnotetext{
* Correspondence: Kshitiz.khanal@kathmandulivinglabs.org;

khanal1990@gmail.com

${ }^{1}$ Kathmandu Living Labs, 1474 Lamtangin Marg, Chundevi, Kathmandu GPO

44600, Nepal

Full list of author information is available at the end of the article
}

data needs associated with both achieving and monitoring almost every UN Sustainable Development Goal (SDG) (see, for example, $[4,5]$ ).

Data in OSM can also support a wide range of other applications, including business enterprise, local governance, and citizens' everyday needs. The use of OSM in these varied contexts is enabled primarily by two factors: (1) a crowdsourcing model that enables anyone to contribute data for any location they are interested in and (2) unrestricted legal use of the data subject only to attribution of the OSM contributors (as per the Open Database Commons License). These factors ensure that data in OSM created by some people for specific purposes can also be used by others for different purposes.

People contribute to OSM in various ways. Contributions by intrinsically motivated individuals in their free time are drivers of open-source and crowdsourcing communities in general, which is also the case in OSM. Organized social events such as mapping parties and mapathons are common in OSM communities. Similar social events also include events organized to collect specific geospatial data, typically for humanitarian purposes in locations where data in OSM are scarce or non-existent [3]. Crisis mapathons, 
which are organized immediately after crises to help first responders, have emerged as a normative response to global disasters; for example, mapathons were organized in several cities around the world to map areas in Nepal affected by the 2015 Gorkha earthquake [6].

Although the importance of such mapping events is well recognized within the OSM community, several studies have exposed their limitations in sustaining contributions from participants beyond the event. Dittus et al. [7] found that many participants who were "activated" during mapping events discontinued mapping when they returned home. These findings indicate that engaging potential contributors only for the duration of a mapping event results in minimal data generation and contributor retention, severely limiting the potential of engaging contributors to generate geospatial data and reducing the coverage, quality and detailed attributes of the data in OSM as a result.

The coverage of OSM is generally limited in economically underdeveloped regions in comparison with their affluent counterparts. These regions also have a greater need for open and free geospatial data to address not only their development challenges but also natural disasters, which often have a greater impact due to economic, social, political and cultural vulnerabilities [8]. Nepal, a landlocked country in South Asia classified by the United Nations as one of the least developed countries (LDCs), is one such case. Although large cities in Nepal, such as Kathmandu and Pokhara, are densely mapped in OSM, rural areas are sparsely mapped, if at all. Further, Nepal is among the 20 most disaster-prone countries in the world [9]. The data gaps in rural areas put the majority of Nepal's population at greater risk in the event of disasters such as earthquakes, landslides, floods and glacial lake outburst floods. The data gaps also limit other potential individual, institutional and community benefits from open, online geospatial data.

Data gaps in OSM in places such as rural Nepal reflect a data divide; combined economic and digital divides have resulted in limitations in availability of big data, open data and crowdsourced data among other types of data in some areas [10-12]. Such a data divide undermines the SDG agenda to "leave no one behind" and "endeavour to reach the furthest behind first" [13], underscoring the importance of identifying strategies to help ensure that open data tools-which were intended to democratize knowledge-do not in fact reinforce inequitable data access.

This study examines the efficacy of a pilot strategy that we call Digital Internship and Leadership (DIAL), which is designed to address data gaps in OSM in rural Nepal by engaging youth in mapping through a virtual internship programme. The efficacy of the pilot strategy is measured in terms of geospatial data generation and youth leadership development.

The remaining sections of the article are structured as follows. In Section 2, we discuss academic and nonacademic work related to contributor engagement, targeted mapping initiatives, and virtual internship, among other topics. In Section 3 (Methodology), we review the DIAL programme design, recruitment, implementation and assessment. In Section 4, we present and discuss our findings. We also describe the study limitations and suggest directions for future research. In Section 5, we present our conclusions.

\section{Related work}

Various studies have explored the connection of contributor engagement approaches and geospatial data generation in OSM. Haklay \& Weber [14] highlighted the role of mapping parties as social events organized by the OSM community to create content in OSM and support vibrant social communities around the OSM project. Several studies (e.g. $[3,15,16])$ have documented various individual mapping events and their impacts in terms of data quality, geospatial data generation, and contributor retention. Bégin, Devillers, Roche, \& Group [17] studied the enrolment of contributors in OSM and found that external events were correlated with high rates of enrolment, suggesting that external events might assist in recruiting contributors. However, Hristova, Quattrone, Mashhadi, \& Capra [18] studied 94 mapping parties around London from 2007 through 2011 and found that such social events failed to retain newcomers but helped retain experienced users. The findings of Hristova et al. [18] suggest that employing social events as the dominant mode of recruiting OSM contributors might be insufficient to eliminate data gaps in OSM. Mapping parties and mapathons help generate data, but most mappers appear to be unlikely to continue mapping on their own, even if they may be motivated to pursue mapping $[7,19]$. In a study of contributors' withdrawal from OSM, Bégin, Devillers, \& Roche [20] discovered that a large majority of participants withdraw during a short "assessment" phase in which contributors explored the project to determine if they would engage in the long term.

Over the last decade, nonprofits, business enterprises and academia have adopted new approaches to encourage sustained, more diverse contributor engagement in OSM to address urgent data needs in specific geographic areas through "targeted mapping initiatives" [21]. Targeted mapping initiatives are a form of "organized editing" or "directed editing" in which organizations direct editing activities by providing some form of benefit to mappers [22]. For instance, Map Kibera [23], started in 2009, engages locals to map Kibera, the largest slum in Africa, 
located in Nairobi, Kenya. Information added to maps of otherwise digitally neglected areas have led to policy changes and increased resources for development [24]. Crowd2Map Tanzania [25], started in 2015 in Tanzania, maps areas where girls are at risk of female genital mutilation so activists can better find them. A total of (at least) 1.2 million map edits in OSM can be attributed to Crowd2Map as of January 02, 2019, based on the Missing Maps leader board [26]. Such local mapping initiatives help the development of these scarcely mapped regions by engaging local contributors for specific purposes for longer periods of time.

Although Map Kibera and other emerging targeted mapping initiatives are well known within the OSM community, there has been limited scholarship focused on their geospatial data generation and contributor engagement. Among the initiatives that have been studied is YouthMappers [27], a global network of university faculties that engage students in mapping to support crisis responders. YouthMappers made a total of 15,695,600 map changes in OSM between April 2016 and July 2017 [28]. Of the YouthMappers, $40 \%$ are estimated to be female [29]. Some US and Canadian YouthMappers have also participated in virtual internship programmes at USAID Geocenter [3]. Virtual internships are internship programmes in which interns work remotely and communicate through virtual means, reflecting the practices of a growing virtual workforce, to facilitate a transition from study to work. Most virtual internships have been offered in technology-dominant fields, such as information management, engineering, biotechnology, and design thinking [30-32]. These YouthMapper interns, who are generally among the more experienced YouthMappers, participate in reviewing data contributed by their peers [28]. Humanitarian OpenStreetMap Team (HOT) also conducted a virtual internship programme in which the interns supported mapping and validation for malaria mapping projects; a total of 65 individuals participated in the 4-8 week internships, with the majority of interns remaining engaged for 4-6 weeks [33].

While these targeted mapping initiatives suggest new ways of engaging mappers in OSM, there is no clear evidence that these approaches will lead to mappers' sustained engagement or a substantial increase in data in OSM. Participating mappers' civic skill development has also received little attention. This implementation study attempts to fill these knowledge gaps. More specifically, the study addresses two primary guiding questions:

1. Does a programme designed to develop digital leadership skills in addition to mapping skills attract and sustain engagement from a diversity of participants?
2. Does a programme that engages mappers for a sustained period of time help fill data gaps in under-mapped places?

\section{Research methods}

This study employed an action research approach to design, conduct and assess a strategy to supplement existing modes of contributor engagement in OSM. The research, led by practitioners, followed an iterative and cyclical process of strategic planning, action, observation, and critical and self-critical reflections to revise the research plans, as defined by Zuber-Skeritt [34]. An action research methodology enriches scholarly understanding through rigorous experimentation and reflection on actions taken in real social settings and provides valuable insights into improving existing practice.

In this study, we designed, explored and documented a targeted mapping initiative with a virtual internship component that was embedded in a youth leadership and internship programme in Nepal. This programme engaged Nepalese youth for a long period of time to contribute to critical data gaps in rural regions while aiming to empower the youth as civic actors in the process. We used a virtual internship strategy with largely remote participation so that the interns could use their spare time to map rural Nepal from their own homes while developing skills relevant to this digital age (the interns were trained via in-person gatherings before the internship began and occasionally met during the internship period).

The design of the intervention strategy-the DIAL programme - was informed by our understanding of the limitations of mapping events as a strategy to generate data in OSM and the potential of engaging youth in targeted mapping, as discussed in Section 2. DIAL is a virtual internship programme conducted by Kathmandu Living Labs (KLL), a not-for-profit civic-technology company based in Kathmandu, Nepal, in which recent Nepalese high school graduates and undergraduate students from various academic backgrounds map remote and vulnerable areas in OSM, as well as undertake tasks to enhance their digital leadership skills. The programme is similar to other virtual internships such as YouthMappers, as the interns perform their tasks virtually and focus on specified under-mapped locations that are typically distant from their homes. However, DIAL is not entirely virtual. Youth training is carried out in-person, and there are in-person meetings with interns during their internships. We define 'digital leadership' as leadership in the digital age that promotes public good using digital tools; digital leadership involves developing digital skills and using them to address societal or ecological issues. An objective of the programme is to help interns become digital leaders through practising skills such as 
online mapping, blogging, and working remotely, in addition to leadership skills such as critical thinking, communication and civic awareness. These skills are promoted as providing both public benefit and a competitive professional advantage.

The DIAL programme was implemented in two cohorts so that the lessons learned from the first cohort could be used to inform and improve the design of the second cohort. The cohorts were coordinated by several KLL staff members with expertise in mapping and youth engagement. Each cohort was documented via a combination of KLL staff training agendas and meeting field notes, student assignments, and required student blog posts and reports. DIAL participant outcomes with respect to mapping quantity were assessed based on the number of map changes made in OSM; leadership learning outcomes were assessed based on participants' reflections in their blog posts and reports written as part of the internship.

\section{DIAL programme recruitment and participation}

Both of the DIAL cohorts' activities were documented and analysed. DIAL is targeted towards undergraduate students or recent graduates from all academic backgrounds. The applications were submitted through an online form and included questions about the applicants' backgrounds and interests in the programme. In Cohort II, we also required the applicants to upload their CVs. Candidates were selected based on the scores assigned by the programme coordinators to their online applications, CVs and telephone interviews. The applicant information is presented in Table 1.

Among the 10interns selected for Cohort I, two interns did not complete the programme. One individual left after the initial training, having decided that the internship would not support his academic training (forestry). The other person did not provide a reason for withdrawing. In Cohort II, one selected intern withdrew prior to completing the initial training due to lack of time, and two others were unable to attend the training due to personal reasons.

\section{Training}

The interns participated in a 4-day orientation training that took place at an in-person gathering before the internship began. The training curriculum included remote mapping (Java OpenStreetMap and iD Editor), field mapping (OSM Tracker for Android, Field Papers) and geospatial data visualization (Carto). While Cohort I met for $4 \mathrm{~h}$ each day, Cohort II met for $7 \mathrm{~h}$ each day, as Cohort I interns recommended increasing training

Table 1 Applicant information

\begin{tabular}{|c|c|c|}
\hline Applicant information & Cohort I & Cohort II \\
\hline Selected interns & $\begin{array}{l}.5 \text { males } \\
.5 \text { females }\end{array}$ & $\begin{array}{l}.15 \text { males } \\
.7 \text { females }\end{array}$ \\
\hline Interns who completed the programme & $\begin{array}{l}.3 \text { males } \\
.5 \text { females }\end{array}$ & $\begin{array}{l}\cdot 12 \text { males } \\
\cdot 7 \text { females }\end{array}$ \\
\hline Male applicants & 26 & 33 \\
\hline Female applicants & 12 & 12 \\
\hline Age range & Data unavailable & $18-29$ years \\
\hline Background & $\begin{array}{l}\text { - Geomatics Engineering } \\
\text { - Architecture } \\
\text { - Crisis Management } \\
\text { - Management } \\
\text { - Forestry }\end{array}$ & $\begin{array}{l}\text { - Geomatics Engineering } \\
\text { - Computer Science and Engineering } \\
\text { - Electronics Engineering } \\
\text { - Management } \\
\text { - Public Health } \\
\text { - Mechanical Engineering }\end{array}$ \\
\hline Geographic location (permanent address) & $\begin{array}{l}\text { Various districts of Nepal such as } \\
\text { - Kathmandu } \\
\text { - Kaski } \\
\text { - Nuwakot Arghakhanchi } \\
\text { - Kavre }\end{array}$ & $\begin{array}{l}\text { Various districts of Nepal such as } \\
\text { - Kathmandu } \\
\text { - Kaski } \\
\text { - Lalitpur } \\
\text { - Tanahun } \\
\text { - Parbat } \\
\text { - Sindhuli } \\
\text { - Kavre } \\
\text { - Bhaktapur } \\
\text { - Kaski } \\
\text { - Sunsari } \\
\text { - Nawalparasi } \\
\text { - Rautahat }\end{array}$ \\
\hline Geographic location (temporary address) & $\begin{array}{l}\text { - Kathmandu } \\
\text { - Kaski }\end{array}$ & $\begin{array}{l}\text { - Kathmandu } \\
\text { - Kaski } \\
\text { - Nepalgunj }\end{array}$ \\
\hline
\end{tabular}


hours. Lectures from and interactions with experienced professionals from various fields related to digital leadership were also integrated into the training. Lectures and discussion on community as curriculum, digital volunteerism through mapping and digital media and current affairs, as well as experience sharing with young professionals were arranged for Cohort I. Similar lectures and interactions were arranged for Cohort II.

\section{Internship}

The two-month internship had interns focus on mapping various areas in rural Nepal (such as places in Kanchanpur, Mugu, Jajarkot districts, flatlands of Western Nepal and flood-affected areas of Eastern Nepal); neither deadlines nor minimum mapping targets were assigned for mapping tasks. Separate hash-tags were used for each cohort to track map changes made as part of the program. Interns also performed other tasks to develop their digital leadership skills, including reading and summarizing articles about OSM and civic awareness and blogging about DIAL experiences.

Communication with and among interns was facilitated through telephone, Google Group, social media and several in-person gatherings. Tasks were assigned via Google Group. Remote talks from humanitarian mapping leaders were organized to help interns understand the broader implications of their mapping efforts. Intern feedback was collected through a final report and presentation slides submitted at the end of the internship period.

The Cohort II program design was modified slightly, reflecting experience with and direct feedback from Cohort I. In order to understand the factors that motivate youth to join DIAL, we conducted a survey of Cohort II. In addition, we increased the internship duration from 2 months to 3 months.

\section{DIAL program assessment}

Twenty-seven interns participated in DIAL across the two cohorts, including 12 young women and 15 young men from multiple locations with varied disciplinary interests. Program assessment examined their motivation, productivity and development of digital leadership.

\section{Participation motivation}

For Cohort II we examined the interns' motivations to participate in the programme in the outcome assessment. Participant motivations were not assessed for Cohort I. The assessment was carried out using a survey that asked the interns to indicate the role of following factors in their decisions to apply for the programme:

- Learning to map

- Obtaining their first professional job experience
- Contributing to society

- Learning digital leadership skills

- Meeting new people and making friends

- Making productive use of their free time

- Becoming associated with KLL

- Understanding geography and society through mapping

- Learning about information technology

The respondents indicated the influence of each factor using a five-point scale, with "1" signifying little influence in their decisions to apply for the programme and " 5 " signifying a substantial influence.

\section{Intern productivity}

We examined DIAL's contribution to filling data gaps in under-mapped areas in Nepal by assessing intern productivity-the amount of geospatial data produced by the two cohorts, both during their programmes and for 3 months afterwards.

The data for the daily map changes made by the DIAL interns were extracted from the OSM server. OSM provides weekly updated changeset (sets of map changes uploaded to the OSM server in one instance) data in PlanetOSM [35]. Osmium [36] was used to process these data to filter the changesets within the target time frame. The same process was repeated to filter out the data for a particular OSM user. This approach provided us with small amount of workable XML data in a compressed format. These data were then extracted to obtain the .osm file. A NodeJS-based package called "xml2json" was used to generate JSON data from this .osm file. Then, the number of map changes for a particular date was counted by adding the changes in each changeset (provided as 'num_changes') falling within that date.

We also considered the interns' baseline background in geography to explore whether there was a relationship between this training and their level of data contribution during and after the programme.

\section{Digital leadership development}

Finally, we assessed the participants' development of digital leadership skills. Key data sources included the reports and blog posts submitted by the participants. We analysed these materials for evidence of emerging interest in civic life and commitment to civic participation, as well as self-reports of professional skill development (e.g., writing, presenting, and time management).

\section{Results and discussion}

The findings suggest that the DIAL programme attracted and engaged a diversity of participants in terms of gender, professional interests and geographic areas of residence. Most participants were university-level students in academic 
domains such as business administration, crisis management, architecture, public health, computer science, and geomatics engineering. The participants were originally from different places in Nepal, both urban and rural, but were studying in large cities such as Kathmandu and Pokhara. In the duration of a few months during the programme, they produced a substantial amount of geospatial data for under-mapped areas, and some participants sustained their participation beyond the programme time frame. In addition, the DIAL participants reported a variety of impacts on their spatial awareness and digital leadership skills.

\section{Participant motivation}

Among the various potential motivations to apply to the programme that were rated by Cohort II, learning digital leadership skills emerged as the most important, followed by contributing to society, meeting new people and making new friends, and learning to map, in that order. Learning digital leadership skills, which was emphasized through programme elements such as practising working remotely and regularly convening with mentors and peers, may have helped sustain participants' engagement throughout the internship period. This finding suggests that making maps was a lower priority, primarily viewed by interns as a means to gain digital leadership skills and contribute to society. The findings resonate with those of Hite et al. [37] that students were involved in the YouthMappers network to contribute to real world issues and social change through mapping in addition to increasing their personal understanding of geography.

We recognize the potential for biases in these findings, as respondents tend to avoid extreme responses or choose responses that they believe will potentially please the researcher [38]. In addition, we administered this survey to a relatively small population. Nonetheless, these findings suggest the potential of embedding efforts to expand youth participation in mapping in more broadly framed youth leadership programming, as well as the importance of further research in this area.

\section{Intern productivity}

We found that the eight DIAL Cohort I interns made 705,271 map changes in a period of 2 months. The 19 Cohort II interns made 1,223,670 map changes over a period of 3 months. While the data quality was not assessed, the interns were monitored by geospatial data professionals, and feedback was provided when necessary by the KLL staff coordinator. The interns also validated each other's map edits. Although it is difficult to compare the amount of geospatial data generated by DIAL with that of other targeted mapping initiatives due to differences in programme design and data availability,
DIAL generated a substantial amount of map data in typically under-mapped places of rural Nepal.

\section{DIAL cohort comparison}

The number of interns in Cohort II was double that of Cohort I, and the duration was 1 month longer. However, the amount of map changes increased by only 1.73 times. This finding highlights the importance of experimentation in programme design to maximize geospatial data generation. We hypothesize that remote mentoring, feedback and coordination with interns was potentially less effective with more than double the number of interns, while the staff resources remained similar to that of Cohort I. An empirical study by Dittus \& Capra [39] found that verbal rewards and peer feedback were effective in newcomer retention. We also note the possibility that the interns in Cohorts I and II were motivated by different interests, which translated into greater/less time spent on mapping. However, we are unable to explore these possibilities, as we did not collect motivation data for Cohort I or detailed data on staff engagement with interns for either cohort. The impacts of participant motivation and the role of programme facilitators with respect to participant mentoring are important areas for further research.

\section{Interns' academic backgrounds and mapping outcomes}

Interns' academic backgrounds ranged from business administration to architecture to crisis management to geomatics engineering. ${ }^{1}$ There were more programme applicants and selected participants with academic backgrounds in geomatics engineering than those with backgrounds other fields. Interns with backgrounds in geomatics engineering, arguably because of their understanding of the value of open geospatial data and the direct link between mapping and their career prospects, were found to be more active in mapping tasks.

Although interns with backgrounds in geomatics engineering were also new to OSM at the beginning of the internship, they mapped more on average than the other interns during the internship period. During the second and third months after the Cohort I internship, two geomatics engineers mapped in both months and one mapped for 1 month, while the rest of the interns (who did not have backgrounds in geomatics engineering) stopped mapping, as shown in Fig. 1. In the figure, we have marked the end of each month on the horizontal axis. We did not consider the month directly after the internship to observe continuity, as the interns were asked to make up days they missed during the scheduled internship at that time.

\footnotetext{
${ }^{1}$ Geomatics engineering is an emerging discipline in engineering that deals with collection, processing, analysis and other operations related to geospatial information.
} 


\section{Monthly map changes by DIAL Cohort I}

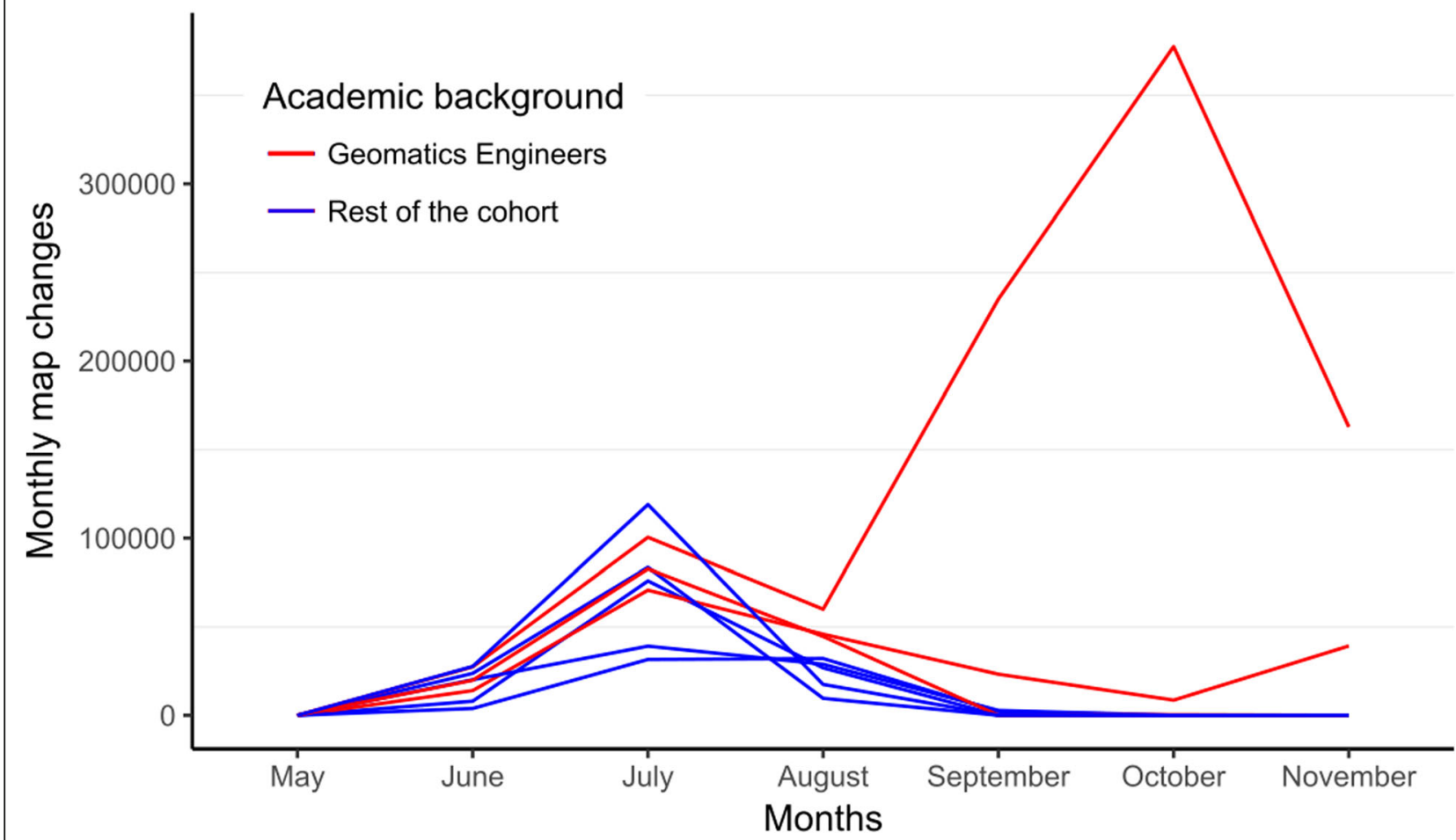

Fig. 1 Monthly map changes by DIAL Cohort I (June training and July-August internship). The total map changes made by both sets of Cohort I interns each month are plotted with lines. The end of each month is marked on the horizontal axis

The Cohort II outcomes were similar, with one geomatics engineer continuing to map during the second and third months after internship, while the other intern also continued mapping at somewhat higher levels, as shown in Figs 1 and 2.

In each cohort, one student with a background in geomatics engineering was an outlier whose contributions overshadowed those of his or her peers. During the second and third months after the internship, three Cohort I interns and three Cohort II interns continued to map in OSM. Among those six interns from both cohorts who continued mapping, only one (from Cohort II) did not have a background in geomatics engineering. Yang, Fan, Jing, Sun, \& Zipf [40] found that prolific contributors are driven by enthusiasm, a sense of responsibility or related careers. These findings suggest that participants with a greater understanding of the value of data in OSM and/or potentially a greater likelihood to use OSM professionally might be more likely to be prolific and maintain their participation; however, this issue also requires further study with a larger population and consideration of the role of other factors, such as gender, socio-economic status, household organization, and personal motivators.

\section{Digital leadership development}

Interns from both cohorts reported in their blogs and final reports that DIAL improved their skills, increased their civic awareness and provided important professional experience. For example, one intern noted that she "improved ... reading, writing and presenting skills." Other interns described their improved time management skills, which some highlighted as an important professional skill, while others underscored the enhancement of their ability to "serve society voluntarily."

Some interns explained that mapping helped them look at their surroundings in new ways. For example, one intern shared, "Something I noticed was that I started looking around and noticing places I would probably have ignored; mapping made me aware of my surroundings, and I would discover facts and details I might not have discovered otherwise." Another intern noted, "Reading about the aspects of society that a map can reflect and realizing it practically by mapping was illuminating; I got to glimpse the socio-economic conditions of people of different parts of Nepal." Another intern appreciated field data collection as offering experience with "how to deal with people in communities" and how to access the types of information they held for broader public benefit. Interns also indicated that the internship helped them "experience a professional life."

The intern reports indicate not only that the interns were contributing their spare time to fill data gaps in OSM but also that DIAL participation had impacts on the 


\section{Monthly map changes by DIAL Cohort II}

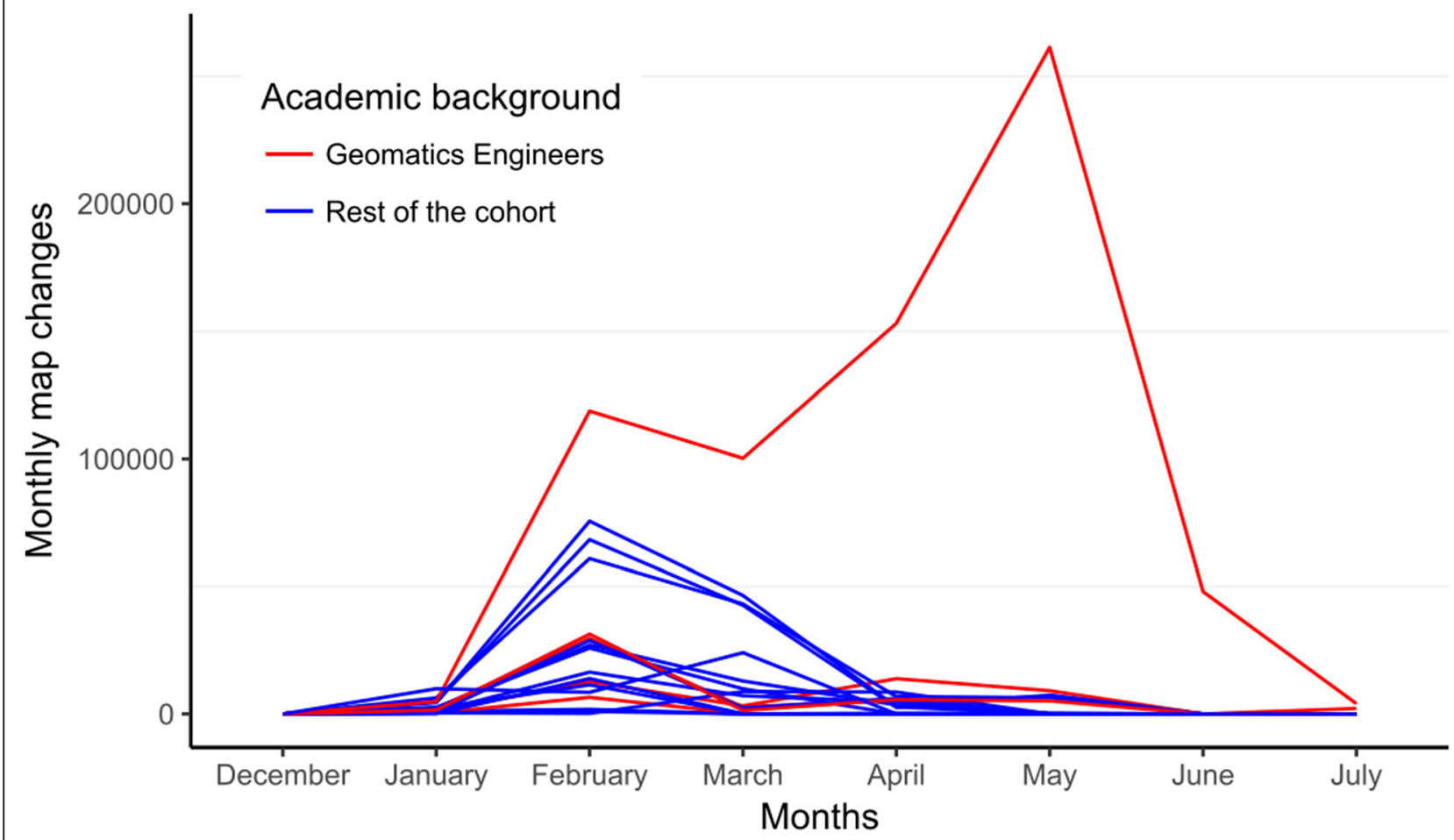

Fig. 2 Monthly map changes by DIAL Cohort II (January training and February-April internship). The total map changes made by both sets of Cohort II interns each month are plotted with lines. The end of each month is marked on the horizontal axis

interns' skills and worldview, reflecting others' findings that the process of mapping changes not only the map but also the mappers. Participation in mapping events, commonly humanitarian mapping, has been found to increase mappers' understanding of the power of mapping to help society; for example, a study of a mapathon designed for primary school children found that the mapping event made students understand the social relevance of mapping ("maps save lives") and provided an opportunity to discover something about different people and ways of life [41]. Engagement in using open source tools to collect geospatial data and increased awareness of humanitarian challenges in other parts of the world nurtures a socially engaged population [3].

\section{Limitations and direction for future research}

The exploratory nature of this research imposed several limitations. First, the study population was small, and we did not have a well-matched control group. We primarily considered the impact of the programme in terms of the amounts of geospatial data generated in undermapped locations. Although the data quality of the contributions was monitored and feedback was provided to interns to minimize errors, a thorough study of the data quality of contributions made in remote settings would provide additional useful knowledge for practitioners.
Additional data collection on participant civic learning and whether and how civic learning translates into civic action would be an important extension of this research. Additional data collection and an in-depth analysis to assess the effects of participant characteristics and factors, such as the engagement of programme coordinators with interns on mapping outcomes, would be helpful.

The study also points to areas of potential interest in OSM scholarship. Inquiry into the development of digital leadership skills and the potential to link mapping with youth leadership, civic engagement and professional learning is promising. Further comparison of targeted mapping initiatives such as DIAL to crowdsourcing approaches to contributor engagement other than mapping events could help increase understanding of the efficacy of these approaches.

\section{Conclusion}

Existing approaches to engaging new contributors to the OSM community have been inadequate for underdeveloped regions on the wrong side of the geospatial data divide. To address this issue, we designed and conducted a largely virtual internship programme called Digital Internship and Leadership (DIAL) and assessed its potential to fill critical geospatial data gaps in rural Nepal. 
Through DIAL, young people (undergraduate students and recent graduates) from various academic, demographic, and regional backgrounds were recruited as interns to perform remote mapping tasks in OSM, along with tasks that helped them hone their skills in areas such as reading, writing, blogging, critical thinking and presenting. The programme sustainably harnessed the potential of young people to contribute to communities through digital volunteerism while also providing a platform to improve their digital leadership skills. The programme also created geospatial data in Nepal's under-mapped regions.

DIAL helped remotely map under-mapped localities, creating basemaps with basic features, such as buildings, roads, and streams. These maps can be complemented with hyperlocal data (secondary attributes) of such places, such as names, contact numbers and other details. Designing a similar programme for and with local people, integrating remote mapping and field mapping, may further help address local needs.

Various studies have acknowledged the increased awareness of societal issues in mappers because of mapping. However, this programme was intentionally designed to enhance civic awareness and digital leadership skills, which seems to have motivated participation. We collected some evidence suggesting that students with academic backgrounds related to geography are more prolific in mapping and are more likely to continue mapping on their own, although further data collection and analyses are required to make this assessment.

Our self-assessment of the DIAL programme informs both ongoing programme development and implementation at KLL and contributes to emerging research on the potential role of youth engagement in building critical open, geospatial data repositories. This study also highlights the emerging role of targeted youth mapping initiatives as a mode of contributor engagement in OSM to address urgent data needs. The approach and findings discussed in this article can be used to design and assess targeted mapping and crowdsourcing initiatives. There is a need for more in-depth exploration of contributor engagement in targeted mapping, with careful attention to how to cultivate and sustain participation by populations committed to mapping under-represented areas, as development practitioners "endeavor to reach the furthest behind first [13]."

\section{Abbreviations \\ DIAL: Digital Internship and Leadership; HOT: Humanitarian OpenStreetMap Team; JOSM: Java OpenStreetMap; JSON: JavaScript Object Notation; KLL: Kathmandu Living Labs; LDC: Least Developed Country; OSM: OpenStreetMap; SDG: Sustainable Development Goal; UN: United Nations; XML: eXtensibel Markup Language}

\section{Acknowledgements}

The authors are thankful to staff of Kathmandu Living Labs for helping in implementation of the program, data extraction and providing suggestions to improve the manuscript. We are also grateful to GIScience/Geoinformatics
Research Group of University of Heidelberg for helping us to gather data of OpenStreetMap contributions made by participants. We also acknowledge contributions from our friends in Humanitarian OpenStreetMap Team and Crowd2Map Tanzania in providing information that helped in improving our argument. We are also thankful to the anonymous reviewers who provided valuable suggestions to improve the manuscript.

\section{Author's contributions}

KK \& NRB led research design, implementation, and writing the manuscript. NE informed program design and later supported research design and manuscript writing. All authors have read and approved the final manuscript.

\section{Funding}

The project received funding from USAID through National Academy of Sciences' Partnership for Enhanced Engagement in Research (PEER) grant no. PGA_174206 (Cycle 5). Funding body had no role in the design of the study and collection, analysis, and interpretation of data and in writing the manuscript.

\section{Availability of data and materials}

The datasets used and/or analysed during the current study are available from the corresponding author on reasonable request.

\section{Competing interests}

The authors have no competing interests to declare.

\section{Author details}

${ }^{1}$ Kathmandu Living Labs, 1474 Lamtangin Marg, Chundevi, Kathmandu GPO 44600, Nepal. ²University of California, Davis, USA.

Received: 20 November 2018 Accepted: 30 August 2019

Published online: 21 October 2019

\section{References}

1. Mooney P. Minghini M. (2017) A review of OpenStreetMap data. In: Foody G, See L, Fritz S, Mooney P, Olteanu-Raimond AM, Fonte CC Antoniou V Mapping and the citizen sensor 37-59. London: Ubiquity Press. https//doi. org/https://doi.org/10.5334/bbf.c.

2. Goodchild MF. Citizens as sensors: the world of volunteered geography. GeoJournal. 2007;69:211 https://doi.org/10.1007/s10708-007-9111-y.

3. Coetzee S, Minghini M, Solis P, Rautenbach V, Green C. Towards understanding the impact of Mapathons - reflecting on Youthmappers experiences. Int Arch Photogramm Remote Sens Spat Inf Sci. 2018;42:29-31.

4. Choi J, Hwang M, Kim G, Seong J, Ahn J (2016). Supporting the measurement of the United Nations' sustainable development goal 11 through the use of national urban information systems and open geospatial technologies: a case study of South Korea. Open Geospatial Data, Software and Standards 1(1):4. http://doi.org/https://doi.org/10. 1186/s40965-016-0005-0.

5. Clark C, Maron M, Patel D, Radford T, Soden R, Uithol P (2016). Open mapping for the SDGs: a practical guide to launching and growing open mapping initiatives at the national and local levels. http://www.data 4sdgs. org/sites/default/files/services_files/OpenMappingfortheSDGsGuide.pdf. Accessed 23 April 2019.

6. Poiani TH, Rocha RDS, Degrossi LC, Albuquerque, JPDe. (2016). Potential of collaborative mapping for disaster relief: a case study of OpenStreetMap in the Nepal earthquake 2015. In: Proceedings of the annual Hawaii international conference on system sciences: 188-197, Hawaii. http://doi. org/https://doi.org/10.1109/HICSS.2016.31.

7. Dittus M, Quattrone G, Capra L (2016). Social contribution settings and newcomer retention in humanitarian crowd mapping. Lecture notes in computer science (including subseries lecture notes in artificial intelligence and lecture notes in bioinformatics), 10047 LNCS (November 2014): 179-193. http://doi.org/https://doi.org/10.1007/978-3-319-47874-6_13.

8. Alcantara-Ayala I. Geomorphology, natural hazards, vulnerability and prevention of natural disasters in developing countries. Geomorphology. 2002;47:107-24.

9. MOHA. Nepal disaster report, 2017: the road to Sendai. Kathmandu: Government of Nepal; 2018. http://drrportal.gov.np/uploads/ document/1321.pdf. Accessed April 232019 
10. Andrejevic M. The big data divide. Int J Commun. 2014;8(1):1673-89 http:// doi.org/1932-8036/20140005.

11. Bezuidenhout LM, Leonelli S, Kelly AH, Rappert B (2017). Beyond the digital divide: towards a situated approach to open data. Sci Public Policy, 44(4): 464-475. http://doi.org/https://doi.org/10.1093/scipol/scw036.

12. Cinnamon J, Schuurman N (2013). Confronting the data-divide in a time of spatial turns and volunteered geographic information. GeoJournal, 78(4): 657-674. http://doi.org/https://doi.org/10.1007/s10708-012-9458-6.

13. UN General Assembly (2015). Transforming our world: the 2030 agenda for sustainable development. http://www.un.org/en/development/desa/ news/sustainable/un-adopts-new-global-goals.html\#more-15178. Accessed 22 April 2019

14. Haklay M, Weber P. OpenstreetMap: User-Generated street Maps. IEEE Pervasive Computing. 2008;7:12-8.

15. Dodge M, Perkins C. Reclaiming the map: British geography and ambivalent cartographic practice. Environ Plan. 2008;40(6):1271-6.

16. Mooney P, Minghini M, Stanley-jones F, Building E, Jose S (2015). Observations on an OpenStreetMap mapping party organised as a social event during an open source GIS. Int J Spat Data Infrastruct Res 10:138-150 http://doi.org/https://doi.org/10.2902/1725-0463.2015.10.art7.

17. Bégin D, Devillers R, Roche S, Group F (2017). Geo-spatial information science contributors' enrollment in collaborative online communities: the case of OpenStreetMap. Geo-Spat Info Sci, 5020:1-14. http://doi.org/https:// doi.org/10.1080/10095020.2017.1370177.

18. Hristova D, Quattrone G, Mashhadi A, Capra L. The life of the party: impact of social mapping in OpenStreetMap. In: Proceedings of the seventh international AAAl conference on weblogs and social media. Cambridge: AAAl; 2013. p. 234-43. 8-11 July 2013.

19. Budhathoki NR, Nedovic-Budic Z, Chip) BB. An interdisciplinary frame for understanding Volunteered Geographic Information. Geomatica. 2010;64(1):2010.

20. Bégin D, Devillers R, Roche S (2017). Contributors' withdrawal from online collaborative communities: the case of OpenStreetMap. Int J Geo-Info, 6(11): 1-20. http://doi.org/https://doi.org/10.3390/ijgi6110340.

21. Gardner Z, Mooney P. Investigating gender differences in OpenStreetMap activities in Malawi: a small case-study. In: Proceedings of agile conference. Lund: AGILE; 2018. 12-15 June 2018.

22. Organized Editing Guidelines. https://wiki.openstreetmap.org/wiki/ Organized_Editing_Best_Practice. Accessed 18 April 2019.

23. Map Kibera. http://mapkibera.org. Accessed 18 April 2019.

24. Hagen E (2017). Open mapping from the ground up: learning from map Kibera. http://www.makingallvoicescount.org/publication/openmapping-ground-learning-map-kibera/. Accessed 23 April 2019.

25. Crowd2Map Tanzania. https:/crowd2map.wordpress.com. Accessed 18 April 2019.

26. Missing Maps Leaderboard. http://www.missingmaps.org/leaderboards/ \#/crowd2map. Accessed 2 January 2019.

27. YouthMappers. http://youthmappers.org. Accessed 18 April 2019.

28. Solís P, McCusker B, Menkiti N, Cowan N, Blevins C (2018). Engaging global youth in participatory spatial data creation for the UN sustainable development goals: the case of open mapping for malaria prevention. Appl Geogr, 98:143-155. http://doi.org/https://doi.org/10.1016/j.apgeog.2018.07.013.

29. Holder S (2018). Who maps the world? https://www.citylab.com/equity/201 8/03/who-maps-the-world/555272/. Accessed 7 January 2019.

30. Arastoopour G, Shaffer DW, Swiecki Z, Ruis AR, Chesler NC. Teaching and assessing engineering design thinking with virtual internships and epistemic network analysis. Int J Eng Educ. 2016;32(3):1492-501.

31. Conroy R, Khan R (2009). Integrating virtual internships into online classrooms. J Commer Biotechnol 97-112. http://doi.org/https://doi.org/10. 1057/jcb.2008.35.

32. Franks PC, Oliver GC. Virtual internships: opportunities for experiential learning and international collaboration in digital curation curricula. In: World library and information congress: 77th IFLA general conference and assembly. San Juan: IFLA; 2011. 13-18 August 2011.

33. Firth R. Personal communication; 2019.

34. Zuber-Skerritt $\mathrm{O}$, editor. New directions in action research. London: Falmer Press; 1996.

35. PlanetOSM. https://planet.openstreetmap.org. Accessed 18 April 2019.

36. Osmium. https://osmcode.org/osmium-tool/manual.html\#introduction. Accessed 18 April 2019.

37. Hite R, Solis P, Wargo L, Larsen TB. Exploring affective dimensions of authentic geographic education using a qualitative document analysis of students' YouthMappers blogs. Educ Sci. 2018;8(4):173.
38. Bertram D (2013). Likert scales. http://poincare.matf.bg.ac.rs/ kristina/topicdane-likert.pdf. Accessed April 22, 2019

39. Dittus M, Capra L (2017). Private peer feedback as engagement driver in humanitarian mapping. In: Proceedings of the ACM on human-computer interaction. November 2017. New York: ACM. https://doi.org/https://doi.org/ $10.1145 / 3134675$

40. Yang A, Fan H, Jing N, Sun Y, Zipf A (2016). Temporal analysis on contribution inequality in OpenStreetMap: a comparative study for four countries. ISPRS Int J Geo Inf, 5(1):5. http://doi.org/https://doi.org/10.3390/ijgi5010005.

41. Ebrahim M, Minghini M, Molinari ME, Torrebruno A (2016). Minimapathon - mapping the world at 10 years old. In: Proceedings of EDULEARN16:4200-4208. 4-6 July 2016. Barcelona. https://doi.org/ https://doi.org/10.21125/edulearn.2016.2018.

\section{Publisher's Note}

Springer Nature remains neutral with regard to jurisdictional claims in published maps and institutional affiliations.

\section{Submit your manuscript to a SpringerOpen ${ }^{\circ}$ journal and benefit from:}

- Convenient online submission

- Rigorous peer review

- Open access: articles freely available online

High visibility within the field

- Retaining the copyright to your article

Submit your next manuscript at $>$ springeropen.com 